\title{
Understanding of Intentions in Children with Autism Spectrum Disorder and Intellectual Disability
}

\author{
Nienke Peters-Scheffer ${ }^{1,2}$ (D) $\cdot$ Robert Didden ${ }^{1,3} \cdot$ Hubert Korzilius $^{4} \cdot$ Ludo Verhoeven $^{1}$
}

Published online: 3 February 2018

(C) The Author(s) 2018. This article is an open access publication

\begin{abstract}
This study investigates the understanding of intentions in 100 children with autism spectrum disorder (ASD) and intellectual disability (ID; mean IQ 36) between 2 and 10 years of age. A within-subject design with two conditions was used. In the target condition, the experimenter successfully performed the task; while in the unfulfilled attempt condition, the experimenter attempted but did not successfully completed the task. Children with ASD and ID completed the tasks significantly more frequent and showed less off-task behavior in the target condition than in the unsuccessful attempt condition, which might indicate that children with ASD and ID experience difficulty in understanding the intentions of others. Successful completion of the task after an unsuccessful attempt is predicted by the ability to imitate and behavioral inflexibility and is associated with better performance on receptive and expressive language tests. The latter results are in line with several other studies suggesting a relation between the understanding of intentions and early social communication and language.
\end{abstract}

Keywords Autism spectrum disorder $\cdot$ Intellectual disability $\cdot$ Imitation $\cdot$ Intentionality $\cdot$ Re-enactment task

\section{Introduction}

Children with autism spectrum disorder (ASD) experience difficulty in tests related to other people's thoughts, knowledge, and beliefs (Baron-Cohen 2001). Numerous studies have reported impaired social learning and imitation in children with ASD (see for reviews Rogers and Pennington 1991; Smith and Bryson 1994; Vanvuchelen et al. 2011; Williams et al. 2004). In general, children with ASD perform better on meaningful rather than on non-meaningful gesture imitation tasks, better on motor imitation tasks with objects than on gestural imitation tasks, and better on structured-elicited than naturalistic spontaneous tasks (Ingersoll 2008; Stone et al.

Nienke Peters-Scheffer

n.peters@pwo.ru.nl

1 Behavioural Science Institute, Radboud University, PO Box 9104, 6500 HE Nijmegen, The Netherlands

2 Stichting De Driestroom, PO Box 139, 6660 AC Elst, The Netherlands

3 Trajectum, PO Box 300, 7200 AH Zutphen, The Netherlands

4 Institute for Management Research, Radboud University, PO Box 9108, 6500 HK Nijmegen, The Netherlands
1997). Although evidence is scarce and long-term studies are lacking, (subtle) imitation problems in ASD seem to persist into adolescence and adulthood (Hobson and Lee 1999).

In different cultures, individuals use objects in various ways and objects have several properties and affordances. Consequently, by simply observing an object, the child may not learn or perform the proper action. In accordance to Tomasello's theory of social learning, children need to select the appropriate action based on the comprehension of another person's intentional, goal-directed action and thus attend to both the means and the end result of the behavior to acquire the conventional use of objects, linguistic symbols, and many other aspects of their culture (Tomasello 1999; Tomasello et al. 2005). Research indicates that even infants comprehend intentions underlying actions. For example, infants from 9 months of age respond more patiently when an adult is unable to give them a toy than when the adult is unwilling to give the toy (Behne et al. 2005).

Further evidence of infants' understanding of intentions is provided by tasks with failed (unsuccessful) attempts or mistakes that create a mismatch between the goal of the individual and the demonstrated behavior. To succeed at such tasks, the infant needs to understand the actor's goal instead of simply observing the surface behavior. Using the behavioral reenactment technique, Meltzoff (1995) presented 18-month 
old children with an actor either performing a goal-directed action on an object or an actor who was trying, but failing to perform a certain action on an object (unsuccessful attempt). Two additional groups of 18-month-old infants participated in one of the two control conditions in which objects were randomly manipulated. In contrast to the children in the two control groups, children were able to perform the intended target behavior after seeing an unsuccessful attempt as often as the children who saw the successful demonstration of the complete target action. Additional evidence of infants' ability to differentiate the goal of the action from the surface behavior was provided in another study by Meltzoff (1995) in which he showed 18-month-old children an adult trying, but failing, to pull apart a mechanical device (i.e., pulling apart a dumbbell). Because the object was too big for the children's hands, infants used different means to reach the same end goal (i.e., to pull apart the dumbbell) instead of just imitating the surface behavior. Since then, several authors have used this type of behavioral re-enactment task to replicate and extend Meltzoff's (1995) study. These studies showed that the understanding of intentions is an important part of imitation and that the understanding of others' intentional actions is not innate but develops between 9 and 15 months of age (Bellagamba et al. 2006; Bellagamba and Tomasello 1999; Johnson et al. 2001; Huang et al. 2002).

Since imitation of other people is one of the first fundamental means by which children learn new behaviors and is associated with joint attention, play skills, language, socialization, and enculturation, the difficulties related to imitation seen in children with ASD may have a cascading effect on their development as they might not benefit sufficiently from social mediated learning (Ingersoll and Schreibman 2006; Tomasello et al. 1993; Tomasello et al. 2005; Toth et al. 2006). However, only a few studies report results on the behavioral re-enactment procedure in children with ASD. Aldridge et al. (2000) compared 10 children with ASD aged between 2:2 and 4:2 (years:months) with 10 normally developing infants aged 0:5 to 1:10. Participants were matched on an object concept task and presented with three gestural imitation tasks and three tasks of the intention condition of the behavioral re-enactment procedure. Against expectations, $50 \%$ of the children with ASD completed all behavioral reenactment tasks, $30 \%$ completed two tasks, and $20 \%$ one task, while of the typically developing children only $20 \%$ completed one task. On the other hand, none of the children with ASD succeeded in any of the gestural tasks, while $50 \%$ of the typically developing children completed all tasks, $30 \%$ completed two tasks, and $10 \%$ one task. However, all but three infants in the control group were younger than 12 months and therefore not expected to pass the behavioral re-enactment tasks (Bellagamba and Tomasello 1999). Further, apart from performance on an object performance task and the absence of language, no information was provided on the developmental ages of the children with ASD, making results difficult to interpret.

Carpenter et al. (2001) used a within-subject design and a control group of 11 children with developmental disabilities to assess the understanding of unfulfilled intentions in 11 children with autism. Children were 2.5 to 5 years old and had a non-verbal developmental age of 2:2 to 4:7 years. In addition to the four conditions used by Meltzoff (1995), the authors added an additional "end-state" condition, in which the experimenter showed the object in the target end state without showing how that end state was achieved (see also Bellagamba and Tomasello 1999). Results indicated that children with developmental disabilities and children with ASD showed the target behavior more often in the intention and target condition than in the manipulation, end state, or baseline conditions. However, children with developmental delays performed the target behavior significantly more often in the intention and end state condition than in the manipulation condition, but this difference was not significant for the children with ASD. A significant positive correlation between chronological age and the relative performance of children with ASD in the intention condition was found, but this correlation was not significant for developmental age. Carpenter et al. (2001) concluded that the children with ASD and the children with developmental disabilities in their study display generally less target behavior than typically developing children. So, the relatively poor performance of the children with developmental delay could explain why an autism specific deficit was not found. Furthermore, included children had a relatively high (developmental) age and could have outgrown the problems in intentions understanding.

Although studies of Aldridge et al. (2000) and Carpenter et al. (2001) provide preliminary evidence on the ability of intention understanding in children with ASD, results are not conclusive. Therefore, the aim of the present study was to assess (a) the understanding of intentions in children with ASD and ID using a withinsubject design in a larger sample with a broader range of (developmental) age, (b) which skills (including developmental age and severity of autism) are associated with the performance on the unfulfilled intention task, and (c) explore the relation between the understanding of intentions and language. We hypothesized that children with ASD would show more target behavior when the experimenter demonstrated the target behavior than when an unsuccessful attempt was demonstrated and that more off-task behavior (no response/other behavior) would be shown after the unsuccessful attempt is demonstrated than when the experimenter demonstrated the target behavior. Second, we expected that children with a lower developmental age would display less target behavior in the unfulfilled attempt condition than children with a higher 
developmental age and larger differences between both conditions were expected for children with a lower developmental age. Third, it was hypothesized that as the severity of autism increases, understanding of intentions decreases. Fourth, as the three subtypes of social interaction and communication (i.e., aloof, passive, and active-butodd) may refer to distinct subgroups of children, children classified with an active-but-odd subtype were expected to have a better understanding of intentions, while those classified as aloof were expected to have the least understanding of intentions (Castelloe and Dawson 1993; Wing and Gould 1979). Fifth, we hypothesized that children with greater behavior inflexibility would experience more difficulty in displaying the target behavior as the experimenter models an unsuccessful attempt than children who show greater behavioral flexibility. Sixth, we expected that children with less early social communication skills would perform less accurately on the behavioral reenactment tasks. Finally, we predicted that performance on the behavioral re-enactment tasks would be associated with scores on the language acquisition tests with lower tests scores associated with poorer task performance.

\section{Method}

\section{Participants}

The participants were 100 children diagnosed with ID and ASD. The 77 boys and 23 girls were between 3:7 and 9:11 years old ( $M=5: 10 ; S D=19.76$ months). All children attended a preschool or school for children with ID in the Netherlands. Children with neurological disorders of known etiology and major physical impairments interfering with data collection (e.g., severe visual impairments and severe epilepsy) were excluded from the study.

Prior to their inclusion, all children received a diagnosis of ASD and ID by a clinician who was independent of the study and in accordance with the DSM-IV or ICD-10 criteria. The diagnoses were confirmed by the Autism Diagnostic Observation Schedule (ADOS) (Lord et al. 2006), the Childhood Autism Rating Scale (CARS) (Schopler et al. 2007), Mullen Scales of Early Learning (MSEL) (Mullen 1995), and the Vineland Adaptive Behavior Scales (VABS; Sparrow et al. 1984). An IQ below 80, in combination with an age equivalent score on the VABS that was at least 6 months lower than the child's chronological age, was used as a criterion to confirm the classification of ID. The Wing Subgroups Questionnaire (WSQ) indicated that 72 children had the aloof subtype, while 18 children had the passive subtype, and 10 the active-but-odd subtype. Characteristics of the participants are listed in Table 1.
Table 1 Characteristics of the participants at baseline $(N=100)$

\begin{tabular}{|c|c|c|c|}
\hline & Mean & SD & Range \\
\hline \multicolumn{4}{|l|}{ Cognitive functioning } \\
\hline Developmental age in months & 23.49 & 8.56 & $4.75-52$ \\
\hline IQ & 35.97 & 16.02 & $10.59-78.78$ \\
\hline Visual reception & 25.78 & 8.94 & $5-54$ \\
\hline Fine motor & 27.48 & 7.79 & $6-51$ \\
\hline Receptive language & 20.64 & 10.81 & $5-55$ \\
\hline Expressive language & 20.05 & 10.12 & $3-48$ \\
\hline \multicolumn{4}{|l|}{ Adaptive behavior in months } \\
\hline Composite & 19.96 & 6.52 & $11-45$ \\
\hline Communication & 24.67 & 10.27 & $12-53$ \\
\hline Daily living skills & 22.67 & 8.53 & $11-47$ \\
\hline Socialization & 21.96 & 6.79 & $11-46$ \\
\hline \multicolumn{4}{|l|}{ Behavior flexibility $^{\mathrm{b}}$} \\
\hline Behavioral flexibility (total) & 10.16 & 6.69 & $0-29$ \\
\hline Behavioral flexibility: objects & 6.33 & 3.87 & $0-16$ \\
\hline Behavioral flexibility: environment & 2.22 & 2.11 & $0-9$ \\
\hline Behavioral flexibility: persons & 0.72 & 0.99 & $0-4$ \\
\hline \multicolumn{4}{|l|}{ Autism } \\
\hline ADOS total & 15.51 & 3.90 & $7-24$ \\
\hline ADOS communication & 5.92 & 1.86 & $2-10$ \\
\hline ADOS social interaction & 9.67 & 2.79 & $2-16$ \\
\hline CARS & 41.23 & 5.69 & $30-53$ \\
\hline \multicolumn{4}{|l|}{ Early Social Communication Scales ${ }^{\mathrm{a}}$} \\
\hline Initiating joint attention & 7.38 & 8.44 & $0-37$ \\
\hline Responding to joint attention & 94.12 & 68.04 & $0-200$ \\
\hline Initiating behavioral request & 23.41 & 7.34 & $2-43$ \\
\hline Responding to behavioral request & 65.99 & 32.73 & $0-100$ \\
\hline Initiating social initiations & 2.62 & 1.82 & $0-8$ \\
\hline Responding to social initiations & 6.65 & 3.35 & $0-18$ \\
\hline \multicolumn{4}{|l|}{ Language } \\
\hline Receptive language (PPVT) & 25.21 & 4.85 & $21-43$ \\
\hline Receptive language (Reynell) & 19.98 & 8.01 & $14-43$ \\
\hline Expressive language (WO) ${ }^{\mathrm{a}}$ & 20.47 & 9.54 & $14-56$ \\
\hline
\end{tabular}

${ }^{\mathrm{a}} n=97$

${ }^{\mathrm{b}} n=92$

\section{Procedure}

Because in individuals with ASD a large variability in behavioral and cognitive characteristics is seen, a within-subject experimental design without a control group was used to lower the possibility of individual differences distorting the results. After data were collected on autism, developmental age, adaptive behavior, and early communication and language, participants were exposed to two conditions (i.e., a target behavior condition and an unsuccessful attempt condition) to measure their understanding of intentions. Children were exposed to five sets of two tasks modeled after Meltzoff 
(1995). Because a within-subject design was used, of each set, one task was completed in the target behavior condition and the other task in the unsuccessful attempt condition. Tasks were presented one at a time in a counterbalanced order to prevent an interaction effect between tasks and conditions. Since more orders (120 per condition) than participants were available for each condition, an order was selected at random. Each order was used only once.

Ethical approval of the study was obtained from the ethics committee of the Radboud University and the ethics committees of some of the sites the participants visited. The children were identified by local preschools and schools for children with ID in the Netherlands. They distributed letters to the parents of children who met the following intake criteria: (1) chronological age between 2 and 10 years, (2) diagnosis of ID and ASD by an independent psychiatrist or psychologist and supported by psychometrically reliable and valid measures, such as the Autism Diagnostic Interview-revised, ADOS, Bailey Scales of Infants Learning, SON-r 2.5-7, and/or the VABS (Lord et al. 1994, Lord et al. 2006; Snijders et al. 1996; Sparrow et al. 1984; Van der Meulen et al. 2002), and (3) the child lived at home so that parents were able to provide information about their child. All parents gave their written consent and did not receive any honorarium for their participation.

Once participants were selected, the first author scheduled in-home interviews with the parents to administer the VABS (Sparrow et al. 1984) and the CARS (Schopler et al. 2007). The latter was completed both on parental interview and behavioral observations conducted by the first author. A week before the parental interview, parents completed the Behavioral Flexibility Rating Scale-revised (BFRS-R; Peters-Scheffer et al. 2008) and the WSQ (Castelloe and Dawson 1993), which was sent out by mail along with an information letter with contact information. Parents returned the completed BFRS-R to the first author during the interview. If not returned during the interview, the first author sent a reminder within 6 weeks with an opportunity to return the completed questionnaires.

In the same month as the interview, five assessments were completed at the preschool or school. These assessments were (a) MSEL, (b) ADOS, (c) Early Social Communication Scales (ESCS) (Mundy et al. 2003), (d) the behavioral re-enactment tasks, and (e) three language tests. The language tests were the Reynell Developmental Language Scales (Van Eldik et al. 1995), the Peabody Picture Vocabulary Test (PPVT) (Dunn and Dunn 1997), and the Schlichting Test for language production (Schlichting et al. 1995). All tests were administrated by the first author and testing occurred in a separated room at the child's preschool or school.

Re-enactment Tasks The experiment was conducted in a distraction free environment at the (pre)school and five sets of two objects modeled after Meltzoff (1995) were constructed for this experiment. The sets of objects and tasks are described in Table 2. After a warm-up period in which the experimenter and the child played with some toys, the child was seated at a table facing the experimenter. The objects were placed within reach of the experimenter, but outside the visual field of the child.

Tasks were presented one at a time in a counterbalanced order to prevent an interaction effect between tasks and conditions. Since more orders (120 per condition) than participants were available, for each condition, an order was selected at random. Each order was used only once. Because a withinsubject design was used, each child received five objects in the target behavior condition and five objects in the unfulfilled attempt condition.

In the target behavior condition, the experimenter demonstrated the target behavior three times in approximately $20 \mathrm{~s}$, while in the unsuccessful attempt condition during which the experimenter attempted, but did not successfully complete the task three times during an (approximately) 20-s trial. Therefore, the child did not see the end stage of the task. After demonstrating each task (i.e., not for the total block of five tasks), the materials were placed on the table in front of the child for a response period of $20 \mathrm{~s}$. No additional verbal cues were provided. After the response period (either in the intention or target behavior condition), the object was removed and the next object was presented using the same procedures described until all 10 objects/tasks had been presented.

Five undergraduate students coded the videotapes. First, the students identified the task (e.g., dumbbell) and the condition (e.g., whether the experimenter demonstrated the target behavior or the demonstrated an unsuccessful attempt) to determine whether the experimenter used the right task and condition for the child. There was a $99.9 \%$ agreement between the condition scored by the students and the condition assigned by the experimenter. Subsequently, the student indicated whether the child displayed the target behavior, performed the task that was supposed to occur in the unsuccessful attempt, showed no response, or engaged in some other behavior. Before the students started coding, the materials were shown and all tasks in the unsuccessful attempt and target behavior condition were demonstrated. After a brief training period, in which several videos were shown to the students, inter-observer reliability was assessed on five videos of five children who were not participating in the current study. A mean kappa of 0.90 (range 0.83 to 1.0 ) was obtained on determining the condition (i.e., unfulfilled attempt vs. demonstration of the target behavior) and a kappa of .85 (range 0.64 to 1.0 ) on whether the child performed the target behavior (Cicchetti 1994). To assess inter-observer reliability during the coding, $28.7 \%$ of the videotapes were randomly selected and independently coded by a second observer. The resulting kappa was 0.91 . 
Table 2 Behavioral re-enactment tasks used in this study resembling the tasks of Meltzoff (1995). Each task was repeated three times. Operational definitions of the child's behavior are provided in italics

\begin{tabular}{|c|c|c|c|}
\hline Pair & Objects & Target behavior & Unsuccessful attempt \\
\hline \multirow[t]{4}{*}{1.} & \multirow[t]{2}{*}{ Dumbbell } & Pull halves apart. & Try to pull halves apart, but one hand slips off (alternating ends) \\
\hline & & The child pulls the dumbbell apart. & When holding the dumbbell, the child's hand or hands slip of. \\
\hline & \multirow[t]{2}{*}{ Plug } & Pull a straight four-pin plug and contra plug apart. & $\begin{array}{l}\text { Try to pull a straight four pin plug and contra plug apart, } \\
\text { but one hand slips off (alternating ends). }\end{array}$ \\
\hline & & The child pulls the plug apart. & When holding the plug, the child's hand or hands slip of. \\
\hline \multirow[t]{4}{*}{2.} & \multirow[t]{2}{*}{ Light } & $\begin{array}{l}\text { Use the stick to push a button attached to a } \\
\text { wooden rectangular to activate a light. }\end{array}$ & $\begin{array}{l}\text { Move the stick towards the button attached to a } \\
\text { wooden rectangular, but miss each time. }\end{array}$ \\
\hline & & $\begin{array}{l}\text { The child actives the light by using the } \\
\text { stick to push a button. }\end{array}$ & $\begin{array}{l}\text { The child moves the stick in a horizontal position in the direction } \\
\text { of the light but misses the button to activate the light. } \\
\text { Hence, the light is not activated. }\end{array}$ \\
\hline & \multirow[t]{2}{*}{ Buzzer } & $\begin{array}{l}\text { Use the stick to push a button attached to a } \\
\text { wooden rectangular to activate a buzzer. }\end{array}$ & $\begin{array}{l}\text { Move the stick towards the button attached to a } \\
\text { wooden rectangular but miss each time. }\end{array}$ \\
\hline & & $\begin{array}{l}\text { The child activates the buzzer by using a } \\
\text { stick to active the buzzer. }\end{array}$ & $\begin{array}{l}\text { The child moves the stick in a horizontal position in the direction } \\
\text { of the buzzer but misses the button to activate the buzzer. } \\
\text { Hence, the buzzer is not activated. }\end{array}$ \\
\hline \multirow[t]{4}{*}{3} & \multirow[t]{2}{*}{ Cube with beads } & Drop the beads into an opening of the cube. & $\begin{array}{l}\text { Move the beads towards the opening of the cube } \\
\text { but miss each time. }\end{array}$ \\
\hline & & $\begin{array}{l}\text { The child lowers the beads vertically } \\
\text { all the way into the cube. }\end{array}$ & $\begin{array}{l}\text { The child lowers the beads vertically onto the } \\
\text { table beside the cube. }\end{array}$ \\
\hline & \multirow[t]{2}{*}{ Cylinder with scarf } & Drop the scarf into the cylinder. & $\begin{array}{l}\text { Move the scarf towards the opening of the cylinder } \\
\text { but miss each time }\end{array}$ \\
\hline & & $\begin{array}{l}\text { The child lowers the scarf vertically all the way } \\
\text { into the cylinder. }\end{array}$ & $\begin{array}{l}\text { The child lowers the scarf vertically onto the } \\
\text { table besides the cylinder. }\end{array}$ \\
\hline \multirow[t]{4}{*}{4} & \multirow[t]{2}{*}{ Rectangle } & $\begin{array}{l}\text { Place a cord loop over a horizontally protruding } \\
\text { peg attached to a wooden rectangle. }\end{array}$ & $\begin{array}{l}\text { Move the cord loop to the horizontally protruding peg, } \\
\text { but miss and drop it on the table. }\end{array}$ \\
\hline & & $\begin{array}{l}\text { By holding the cord between the thumb and index } \\
\text { finger, the child puts the cord loop over the peg } \\
\text { so that the peg protrudes through it. }\end{array}$ & $\begin{array}{l}\text { The child holds the cord between the thumb and index finger } \\
\text { and moves the cord towards the horizontally protruding } \\
\text { peg but drops it within } 5 \mathrm{~cm} \text { of the peg, } \\
\text { without the peg protruding the cord. }\end{array}$ \\
\hline & \multirow[t]{2}{*}{ Triangle } & $\begin{array}{l}\text { Place a flat plastic teddy bear with a hole in the middle } \\
\text { over a horizontally protruding peg attached } \\
\text { to a wooden triangle. }\end{array}$ & $\begin{array}{l}\text { Move the flat plastic teddy bear with a hole in the } \\
\text { middle towards the horizontally protruding peg } \\
\text { but miss and drop it on the table. }\end{array}$ \\
\hline & & $\begin{array}{l}\text { The child puts the hole of a flat plastic teddy bear } \\
\text { over a horizontally protruding peg attached to a } \\
\text { wooden triangle so that the peg protrudes through it. }\end{array}$ & $\begin{array}{l}\text { The child moves the teddy bear towards the horizontally } \\
\text { protruding peg but drops it within } 5 \mathrm{~cm} \text { of the peg, } \\
\text { without the peg protruding the hole. }\end{array}$ \\
\hline \multirow[t]{4}{*}{5} & \multirow[t]{2}{*}{ Two blocks } & $\begin{array}{l}\text { Place one block with a hole over a vertically } \\
\text { protruding peg on a similar block. }\end{array}$ & $\begin{array}{l}\text { Try to place one block with a hole over a protruding peg } \\
\text { on a similar block but let the block slip of. }\end{array}$ \\
\hline & & $\begin{array}{l}\text { The child places the block on a similar block with } t \\
\text { he hole of the first block over the vertically protruding } \\
\text { peg of the other block so that the peg protrudes } \\
\text { through the hole of the block. }\end{array}$ & $\begin{array}{l}\text { The child places the block on a similar block with the hole of the } \\
\text { first block next to the vertically protruding peg } \\
\text { of the other block, making the first block slip of the other. }\end{array}$ \\
\hline & \multirow[t]{2}{*}{ Block and ball } & $\begin{array}{l}\text { Place a ball with a hole over a vertically } \\
\text { protruding peg on a block. }\end{array}$ & $\begin{array}{l}\text { Try to place a ball with a hole over a protruding peg on a } \\
\text { block, but let the ball slip of. }\end{array}$ \\
\hline & & $\begin{array}{l}\text { The child places the hole of the ball over the vertically } \\
\text { protruding peg on a block so that the peg } \\
\text { protrudes through it. }\end{array}$ & $\begin{array}{l}\text { The child places the ball on the vertically protruding } \\
\text { peg with the hole on the side letting the ball } \\
\text { fall down on the table. }\end{array}$ \\
\hline
\end{tabular}

\section{Measures}

The standardized instruments were designed to assess a broad range of skills for both typically and atypically developing children and were chosen for their adequate psychometric properties.
Autism The ADOS is a semi-structured, interactive schedule designed to assess social and communicative functioning in children with ASD (Lord et al. 2006). Based on a parental interview and observations of the first author, the CARS was completed (Schopler et al. 2007). This scale consists of 15 items on social emotional and interaction skills, response to 
sensory information, and language and communication skills to distinguish children with autism from developmentally handicapped children without autism.

As the three subtypes of social interaction and communication (i.e., aloof, passive, and active-but-odd) may refer to distinct subgroups of children with ASD, they were included in this study. Children in the aloof subgroup are characterized by rare spontaneous social approaches to others (except to obtain wants or needs) and by the tendency to reject unsolicited social or physical contact. Although children in the passive subgroup are also characterized by a lack of spontaneous social approaches to others, they typically engage in interactions with others as long as the other structures the interaction. Children in the active-but-odd subgroup are willing to make social approaches to others. However, these approaches are made in a peculiar, naive, or one-sided manner. The WSQ is a questionnaire with 13 behavioral domains (e.g., communication, social approach, play, imitation, motor behavior, resistance to change) on with parents rate their child's behavior on a scale from 0 (never) to 6 (always) for each domain. A summary score is calculated for each subtype and the highest summary score is considered to indicate the child's subtype (Castelloe and Dawson 1993).

Developmental Age The MSEL were used to evaluate cognitive ability in the domains of visual reception, fine motor, expressive language, and language comprehension. The MSEL provide a standardized score for children between 0 and 60 months of age, and due to the chronological age, not all standardized scores could be calculated for the children participating in the current study. Therefore, developmental ages and ratio IQ were used in our analyses. A mean developmental age was calculated based on the developmental ages on the four subscales of the MSEL, while ratio IQ was calculated by the mean developmental age divided by the chronological age of the child and multiplied with 100 (Mullen 1995).

Adaptive Behavior The VABS survey form is a semistructured parent interview that was administered to assess the adaptive behavior on adaptive behavior composite and in the domains: communication, daily living skills, and socialization (Sparrow et al. 1984).

Early Communication and Language The ESCS is a videotaped semi-structured observational instrument to measure initiating and responding to joint attention, behavioral requests, and social interaction by presenting a set of toys and activities to elicit social and communicative behavior in an ecologically valid context (Mundy et al. 2003). The ESCS was administered by the first author and videotapes were scored by four raters, unaware of the exact aim of the study. Inter-rater reliability was assessed using videotaped data from $28.7 \%$ of the children and Pearson's correlations between the paired ratings of the six subscales ranged from .98 to 1 suggesting excellent reliability. Receptive language was measured by the comprehension scales of the Dutch version of the Reynell Developmental Language Scales (Van Eldik et al. 1995) and the PPVT (Dunn and Dunn 1997), while expressive language was measured by the vocabulary test of the Schlichting Test for language production (Schlichting et al. 1995).

Behavioral Flexibility The Dutch version of the revised BFRS$\mathrm{R}$ was used to assess severity of behavioral flexibility (PetersScheffer et al. 2008). One of the parents completed a 3-point Likert-type scale of 16 items referring to specific and unexpected events and changed routines that may prove problematic for children with autism and related developmental disabilities. The BFRS-R yields scores on a total scale and three subscales: flexibility towards objects, flexibility towards the environment, and flexibility towards persons.

\section{Data Analyses}

First, paired sample $t$ tests will be used to measure differences in the target behavior and off-task behavior between the target behavior condition and the unfulfilled attempt condition in order to assess the understanding of intentions in children with ASD and ID. Second, the effect of developmental age on the understanding of intentions will be assessed using a repeated measures analysis. Third, to explore if behavioral flexibility, autism, early social communication, and expressive and receptive language are associated with the target behavior displayed in the unfulfilled attempt condition correlation coefficient will be calculated. Fourth, to test if children classified as active-but-odd have a better understanding of intentions than those classified as aloof or passive, a one-way ANOVA will be conducted with the target behavior displayed in the unfulfilled attempt condition as dependent variable. Subsequently, planned contrasts will be used to compare the scores of children in each subgroup. Fifth, to determine whether the target behavior displayed in the unfulfilled attempt condition can be predicted from other child characteristics, a hierarchical regression will be employed with the frequency of target behavior shown in the unfulfilled attempt condition as the dependent variable and developmental age, target behavior in the target behavior condition, autism severity (total score of the ADOS), behavioral flexibility towards objects, and responding to social initiations as independent variables. Sixth, to explore the relation between the understanding of intentions and language, a multivariate analysis will be performed with the frequency of target behavior in the unsuccessful attempt condition as independent variable and receptive language (both on the Reynell and PPVT) and expressive language as dependent variables. The multivariate analysis will be followed up with an univariate analysis with 
planned contrast (repeated) for expressive language and both tests of receptive language.

\section{Results}

Frequencies of target behavior, unfulfilled attempts, and other behavior were calculated for both conditions. Using paired sample $t$ tests, participants showed significantly more target behavior in the target behavior condition $(M=2.71, S D=$ $1.83)$ than in the unfulfilled attempt condition $(M=1.56$; $S D=1.29), t(99)=8.33, p<.001$. Additionally, more offtask behavior (e.g., no reaction/other behavior) was shown in the unfulfilled attempt condition $(M=2.65 ; S D=1.65)$ than in the target behavior condition $(M=2.20 ; S D=1.81, t(99)=$ $3.95, p<.01)$.

Figure 1 displays the target behavior shown in the target behavior and the unfulfilled attempt condition specified by developmental age. Results of a one-way ANOVA showed that the performance of the children on tasks was significantly affected by the condition and the developmental age of the child, $F(4,91)=4.73, p<.01$. A repeated measures analysis for each developmental age group revealed that the differences between the target behavior condition and unfulfilled attempt condition were significant in each developmental age group; $F(1,17)=5.67, p=.03$ for 9 to 14 month, $F$ $(1,18)=11.50, p<.01$ for 15 to 20 month, $F(1,28)=11.38$, $p<.01$ for 21 to 26 month, $F(1,18)=41.23, p<.01$ for 27 to 32 month, and $F(1,10)=26.67, p<.01$ for 33 to 38 month.

Planned contrasts (repeated) revealed significant changes in the frequency of target behavior in the target behavior condition between children with a developmental age of 9 to 14 and from 15 to 20 month $(t(4)=-4.13, p<.01)$ and between
21 to 26 month and 27 to 32 month $(t(4)=-3.14, p<.01)$, while differences between 15 to 20 month and 21 to 26 month $(t(4)=-1.38, p=.17)$ and between 27 to 32 and 33 to 38 month $(t(4)=-1.11, p=.27)$ were not significant. In the unfulfilled attempt condition, differences in children with a developmental age between 9 to 14 and from 15 to 20 month $(t(4)=-3.14, p<.01)$, between 15 to 20 and 21 to 26 month $(t(4)=-2.10, p=.03)$, and between 27 to 32 and 33 to 38 months, $(t(4)=-2.91, p<.01)$ were significant. However, the difference between children with a developmental age of 21 to 26 month and 27 to 32 month, $(t(4)=-0.11$, $p=.78$ ) was not significant. Due to small sample sizes, children with a developmental age below 9 month $(n=1)$ and above 39 month $(n=3)$ were excluded from the analysis.

Subsequently, partial correlation coefficients controlling for developmental age were calculated to explore which variables were associated with the target behavior displayed in the unfulfilled attempt condition. Results are displayed in Table 3. There were associations with small effects between the target behavior displayed in the unfulfilled attempt condition and behavioral flexibility (total scale), receptive language (PPVT) and the ADOS (total scale and subscales), and associations with moderate effects between the target behavior displayed in the unfulfilled attempt condition and responding to social initiations, behavioral flexibility towards objects, and imitation (Cohen 1988).

Autism severity (ADOS) controlled for developmental age was significantly correlated with the frequency of target behavior displayed in the unfulfilled attempt condition $(r=$ $-.25, p=.01)$, indicating that as the severity of autism increased, the frequency of target behavior displayed in the unfulfilled attempt condition decreased. A visual representation of the association between severity of autism and developmental age is presented in Fig. 2.
Fig. 1 Target behavior performed in the target behavior and the unsuccessful attempt condition broken down by developmental age

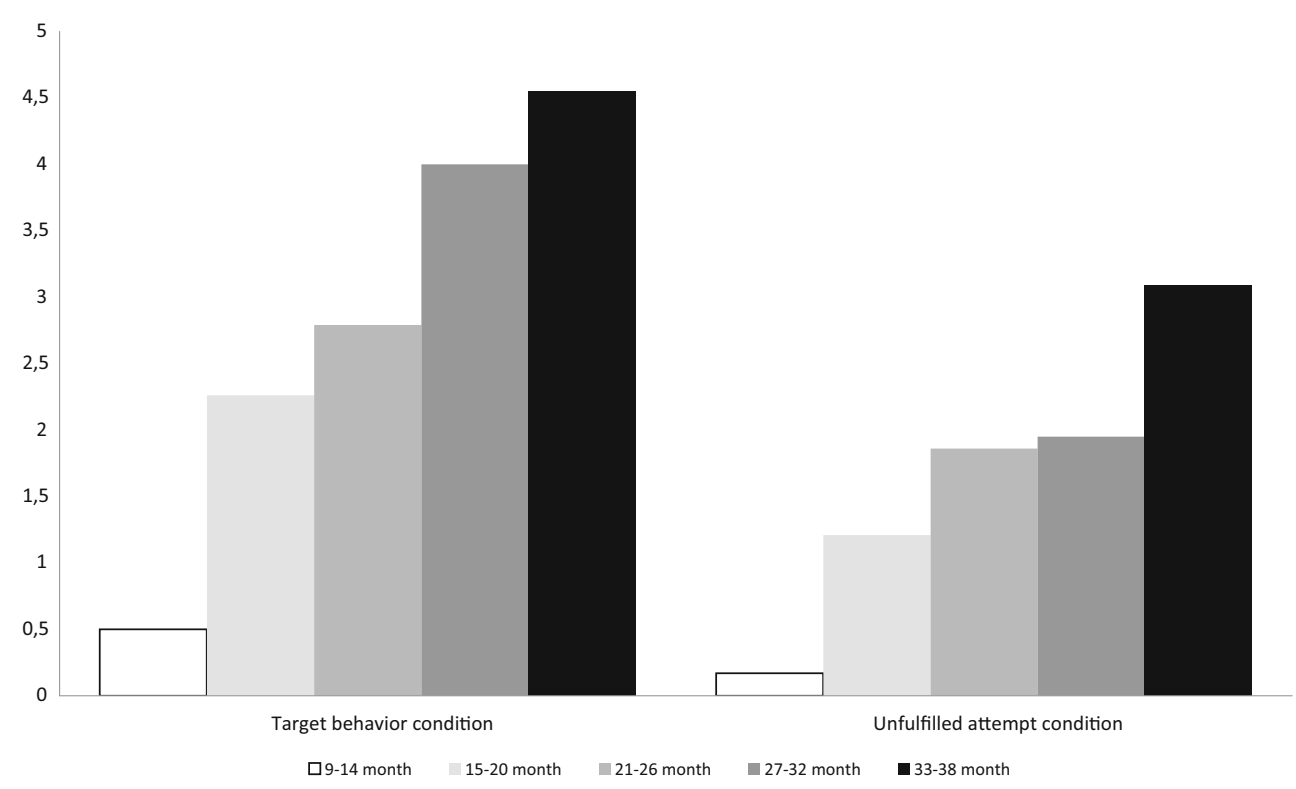


Table 3 Partial correlations with target behavior displayed in the unsuccessful attempt condition controlling for developmental age

\begin{tabular}{|c|c|c|}
\hline & $R$ & $P$ \\
\hline Chronological age & -.09 & .39 \\
\hline \multicolumn{3}{|l|}{ Behavior flexibility $^{\mathrm{b}}$} \\
\hline Behavioral flexibility & .27 & .01 \\
\hline Behavioral flexibility: objects & .32 & .00 \\
\hline Behavioral flexibility: environment & .11 & .29 \\
\hline Behavioral flexibility: persons & .12 & .24 \\
\hline \multicolumn{3}{|l|}{ Autism } \\
\hline ADOS total & -.25 & .01 \\
\hline ADOS communication & -.22 & .03 \\
\hline ADOS social interaction & -.20 & .05 \\
\hline CARS & .05 & .62 \\
\hline \multicolumn{3}{|l|}{ Early Social Communication Scales ${ }^{\mathrm{a}}$} \\
\hline Initiating joint attention & .10 & .32 \\
\hline Responding to joint attention & .20 & .05 \\
\hline Initiating behavioral request & .20 & .06 \\
\hline Responding to behavioral request & .18 & .07 \\
\hline Initiating social initiations & .05 & .64 \\
\hline Responding to social initiations & .31 & .00 \\
\hline \multicolumn{3}{|l|}{ Language } \\
\hline Receptive language (PPVT) & -.18 & .02 \\
\hline Receptive language (Reynell) & -.07 & .51 \\
\hline Expressive language (WO) ${ }^{\mathrm{a}}$ & -.23 & .08 \\
\hline $\begin{array}{l}\text { Frequency target behavior in target } \\
\text { behavior condition (imitation) }\end{array}$ & .47 & .00 \\
\hline
\end{tabular}

Note. $d f=97$

${ }^{\mathrm{a}} d f=94$

${ }^{\mathrm{b}} d f=89$

Furthermore, a one-way ANOVA displayed an overall significant effect of autism subtype on the target behavior displayed in the unfulfilled attempt condition $(F(2,97)=$ $5.82, p<.01)$. Planned contrasts revealed that children with the aloof subtype displayed significantly less target behavior in the unfulfilled attempt condition $(M=1.32, S D=1.27)$ than children with the active-but-odd subtype $(M=2.60, S D=$ $1.17, t(97)=-3.08, p<.01)$, but not less than children with the passive subtype $(M=1.94, S D=1.11, t(97)=-1.93$, $p=.06)$. There was no significant difference in the frequency of target behavior displayed in the unfulfilled attempt condition between children with the active-but-odd and the passive subtype $(t(97)=1.35, p=.18)$. However, the difference between the aloof children and the children with the active-butodd subtype may be explained by the developmental age of the participants, as children in the aloof group had a significantly lower developmental age $(M=20.19 ; S D=6.34)$ than children with the passive $(M=31.08 ; S D=8.67)$ or activebut-odd subtype $(M=31.08 ; S D=8.67)$.

To determine whether the target behavior displayed in the unfulfilled attempt condition can be predicted from other child characteristics, a hierarchical regression was employed with the frequency of target behavior shown in the unfulfilled attempt condition as the dependent variable and developmental age, target behavior in the target behavior condition, autism severity (total score of the ADOS), behavioral flexibility towards objects, and responding to social initiations as independent variables. Table 4 displays the unstandardized regression coefficient $(B)$ and standard error of the unstandardized regression coefficient $(S E B)$ and the standardized regression coefficient $(\beta)$ at each step. $R$ was significantly different from zero at the end of each step. Although a significant predictor was entered alone in combination with the frequency of target behavior displayed in the target condition (i.e., the ability to imitate), developmental age does not longer contribute significantly to the model in steps 2 and 3. All three models significantly improved the ability to predict the frequency of target
Fig. 2 Frequency of target behavior displayed in the unsuccessful attempt condition by developmental age broken down by autism severity group

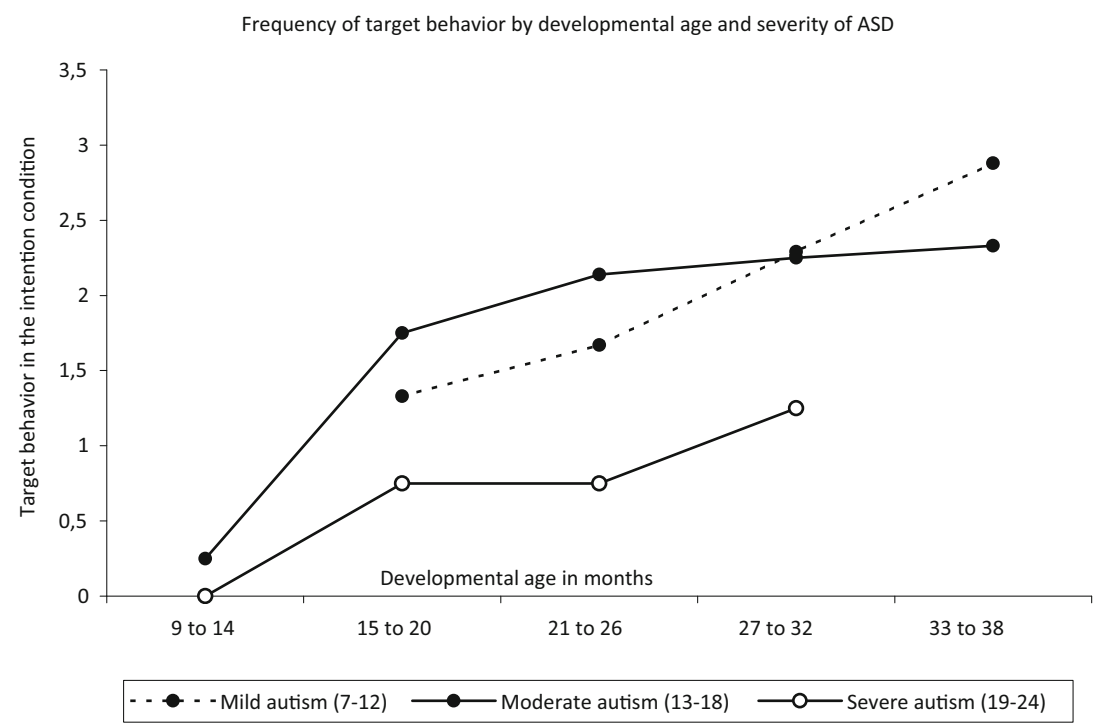


Table 4 Multiple regression with frequency of target behavior in the unsuccessful attempt condition as dependent variable

\begin{tabular}{|c|c|c|c|c|c|c|c|c|c|}
\hline & \multicolumn{3}{|l|}{ Step 1} & \multicolumn{3}{|c|}{ Step 2} & \multicolumn{3}{|c|}{ Step 3} \\
\hline & $B$ & $S E B$ & $\beta$ & $B$ & $S E B$ & $B$ & $B$ & $S E B$ & $\beta$ \\
\hline Constant & -.32 & .34 & & -.10 & .30 & & -.21 & .30 & \\
\hline Developmental age & .08 & .01 & $.55^{*}$ & .03 & .02 & .17 & .02 & .02 & .10 \\
\hline Target behavior (imitation) & & & & .39 & .08 & $.55^{*}$ & .35 & .08 & $.49 *$ \\
\hline \multirow[t]{2}{*}{ Behavioral flexibility: objects } & & & & & & & .08 & .03 & $.23 *$ \\
\hline & \multicolumn{3}{|c|}{$\begin{array}{c}F(1,87)=36.71 \\
p<.001\end{array}$} & \multicolumn{3}{|c|}{$\begin{array}{c}F(2,86)=36.02, \\
p<.001\end{array}$} & \multicolumn{3}{|c|}{$\begin{array}{c}F(3,85)=27.48 \\
p<.001\end{array}$} \\
\hline
\end{tabular}

Note. $R^{2}=.30$ for step $1 ; \Delta R^{2}=.16$ for step $2 ; \Delta R^{2}=.04$ for step 3

$* p<.001$

behavior displayed in the unsuccessful attempt condition. As the predictors responding to social interaction, $t=1.61$, $p=.11$, and severity of autism, $t=-1.64, p=.11$, did not significantly contribute to the models, they were excluded from the analyses. After step 3, in which developmental age, the frequency target behavior in the target behavior condition (imitation), and behavioral flexibility towards objects were included, $49.2 \%$ of the variance was accounted for.

A multivariate analysis was performed with the frequency of target behavior in the unsuccessful attempt condition as independent variable and receptive language (both on the Reynell and PPVT) and expressive language as dependent variables. Target behavior displayed in the unsuccessful attempt condition has a significant effect on language, $\Lambda=.60$, $F(15,246.09)=3.30, p<.01$, even when controlled for developmental age, $\Lambda=.60, F(15,243.33)=3.36, p<.01$.

Univariate analysis for expressive language and both tests of receptive language showed significant effects of the target behavior displayed in the unsuccessful attempt condition on all dependent variables; $F(5,94)=10.27, p<.01$ for the Reynell, $F(5,94)=7.65, p<.01$ for the PPVT and $F(5$, $91)=5.90, p<.01$ on expressive language. Subsequently, per variable planned contrasts (repeated) were used to compare the language scores of children in each category (e.g., ,displaying $0,1,2,3$ or 4 target behaviors) to the previous category. As only one child displayed five target behaviors in the unsuccessful attempt condition, this category was not interpreted in the contrasts. Planned contrasts did not reveal any significant differences in scores between each category compared to the previous category. Descriptives are presented in Table 5.

\section{Discussion}

This study addressed the understanding of intentions in children with ASD and ID between 3 and 10 years of age by assessing (a) the understanding of intentions in children with ASD and ID, (b) which skills (including developmental age and severity of autism) are associated with the understanding of intentions, and (c) exploring the relation between the understanding of intentions and language. A within-subject design with five pairs of parallel tasks based on Meltzoff's (1995) behavioral re-enactment procedure was used. All children completed five tasks in a condition in which the experimenter modeled the target behavior successfully (target behavior condition) and five tasks in which the experimenter tried but failed to perform the target behavior (unsuccessful attempt condition), thereby creating a mismatch between the adult's goal and the demonstrated surface behavior.

Participants showed significantly more target behavior in the target behavior condition than in the unsuccessful attempt condition, which might suggest that children with ASD and ID experience difficulty in interpreting other's intentions. Although Carpenter et al. (2001) also noted that withingroup patterns suggested that children with ASD might have a more simplistic understanding of intentions than other children, our findings are in contrast with the two studies in which evidence for an autism specific deficit was not found (Aldridge et al. 2000; Carpenter et al. 2001). The discrepant findings might stem from the fact that these two prior studies had relatively small samples and the children in the study of Carpenter et al. (2001) had a higher (developmental) age than the children in our study. Because developmental age is correlated to the understanding of intentions, this might explain

Table 5 Means and standard deviations of the developmental age in months on the language test specified by the frequency of target behavior performed in the unsuccessful attempt condition

\begin{tabular}{|c|c|c|c|c|c|c|}
\hline & \multicolumn{2}{|l|}{ PPVT } & \multicolumn{2}{|c|}{ Reynell } & \multicolumn{2}{|c|}{ Schlichting } \\
\hline & $M$ & $S D$ & $M$ & $S D$ & $M$ & $S D$ \\
\hline 0 & 23.08 & 4.43 & 15.38 & 4.00 & 15.27 & 4.54 \\
\hline 1 & 24.92 & 4.83 & 18.42 & 7.17 & 21.21 & 10.61 \\
\hline 2 & 25.87 & 5.15 & 22.52 & 8.25 & 21.95 & 8.99 \\
\hline 3 & 26.29 & 4.24 & 22.24 & 8.20 & 20.29 & 8.98 \\
\hline 4 & 29.29 & 4.35 & 29.86 & 9.30 & 34.00 & 9.56 \\
\hline
\end{tabular}


differences in outcome between studies. Still, because we did not include a control group, it would be premature to conclude that children with ASD have a deficit in intention understanding. However, when compared to 12- to 18-month-old infants, our data suggest that children with ASD with a comparable developmental age might be expected to show less target behavior in both conditions (Bellagamba and Tomasello 1999; Bellagamba et al. 2006; Meltzoff 1995). In typically developing children, intention understanding is reported to develop between 9 and 15 months and in 18-month old infants, the same amount of target behavior is seen after demonstration of the target behavior as after demonstration of the intention of such behavior (see e.g., Bellagamba and Tomasello 1999; Meltzoff 1995). Our study shows that the frequency of target behavior increases as developmental age increases, but that differences between the frequencies of target behavior displayed in the two conditions remain significant in all age groups. This might suggest a delayed development of intention understanding in children with ASD and ID. Further research with a longitudinal design would thus be indicated to further investigate whether children with ASD and ID have a deficit in intention understanding as compared to children with ID only, whether the understanding of intentions is developed in children with ASD, and which variables influence the development of intention understanding and are affected by a lack of intention understanding.

In addition to developmental age, severity of autism-as measured by the ADOS - seemed to influence the understanding of intentions. This relation was not found for autism severity on the CARS. However, the ADOS composite is comprised of items related to communication and social interaction, while the CARS focuses relatively less on communication and social interaction, as it also contains items related to emotional responses, body and object use, adaptation to change, responses to sensory stimuli, fear, and activity level (Schopler et al. 2007). These CARS items might be less associated with intention understanding than communication and social interaction. Similarly, children with the aloof subtype seemed more impaired in intention understanding than children of the passive or active-but-odd subtype. This seems in accordance to the relation between severity of autism and intention understanding, and typically, a lower IQ is found in the aloof subgroup (Castelloe and Dawson 1993). Furthermore, other imitation studies have also reported a relation between autism severity and imitation abilities (Zachor et al. 2010).

Because children with ASD are reported to experience difficulty in being flexible in their behavior towards their use of objects, behavioral flexibility was also assessed (Didden et al. 2008; Peters-Scheffer et al. 2008). Extracting relevant information from interactions in changing social contexts and persons requires flexibility. Perseverating on familiar and predictable objects, persons, and routines may lead to a failure to attend to and comprehend social and communicative information (Munson et al. 2008). Contrary to our expectations, behavioral inflexibility towards objects was positively associated with intention understanding. As the superficial movements in both conditions are fairly equal (put the ball on the stick versus trying to, but not succeeding to put the ball on the stick), experimenter's movements might have served as an effective model for the child's response to some extent. Children who scored lower on the BFRS-R (i.e., had less behavioral flexibility) were more impaired in terms of exhibiting alternative behavior (e.g., throwing the ball away) and might thus have been more influenced by the experimenter's model (e.g., perform a task with the ball and the stick; not only with the ball or the stick).

A relation between the understanding of intentions and early social communication and the acquisition of language is suggested in the literature and by the data of our study. For example, infants' gaze following behavior at 10 to 11 months of age significantly predicts accelerated vocabulary growth through to 2 years of age (Brooks and Meltzoff 2008). In addition, Heimann et al. (2006) showed that in typically developing children, visual recognition memory, deferred imitation, and turn taking skills predicted communicative gestures, while deferred imitation at 14 months also predicted vocal comprehension.

\section{Limitations}

The results of the study must be understood within the context of its limitations. First, no control group was included. Future studies should include a control group of typically developing children or children with ID only to further investigate the influence of ASD on intention understanding. When including a control group, children should be carefully matched to the experimental group on developmental age, as this seems to be related to the understanding of intentions. Although there seems a relation between intention understanding and (early) communication and language, no data were collected on the participant history related to communication or other treatments that may have impacted the understanding of intentions. Therefore, future studies should control for these treatments. Although high inter-rater reliable was reported between on the videotaped measures and an excellent agreement between the condition (i.e., the target behavior condition and the unsuccessful attempt condition) scored by the coders and the condition assigned by the experimenter, procedural fidelity was not further assessed.

The associations between variables found in this study cannot be interpreted, as evidence of causation and research addressing that changes in the understanding of intentions precedes changes in early social communication and language acquisition is warranted. Using fMRI, recent research found 
that - in contrast to typically developing children - children with ASD do not seem to experience social stimuli as rewarding (Scott-Van Zeeland et al. 2010). According to the social motivation theory, this deficit in the reward mechanism is hypothesized to result in children with ASD spending less time attending to faces, speech, and other social stimuli (Dawson et al. 2005; Schultz 2005). This in turn may lead to problems in terms of acquiring knowledge related to the processing of facial expressions and speech (Dawson et al. 1998; Kuhl et al. 2005). Furthermore, while typically developing children prefer variable feedback which is characteristic for social stimuli, children with ASD prefer the less variable feedback of non-social stimuli (Gergely and Watson 1999).

Such impairments in social processing might also complicate the interpretation of other people's behavior and goals and consequently the selection of relevant behaviors to imitate. In this study, children who responded better to social initiations performed better in intention understanding. This trend was also seen in responding to joint attention and to behavioral requests. Due to misinterpretation of other's goals, children with ASD might select irrelevant behaviors to imitate and thereby they would be expected to be less successful with observational learning approaches compared to typically developing children. There are also data to suggest that children with ASD imitate significantly better in a structured-elicited setting than in a naturalistic-spontaneous condition in which selection of the relevant behavior is necessary (Ingersoll 2008). However, more research is needed to explore whether understanding intentions plays a significant role in selecting relevant behavior to imitate and whether this affects development of social learning in children with ASD.

Lack of intention understanding might also influence the social aspect of imitation. In a sample of 35 typically developing children, Colonnesi et al. (2008) found that the abilities to understand intentions at 12 and 15 months of age predicted the later ability to explain other's actions in a psychological way at 39 months. This suggests that understanding of intentions is one of the first steps towards a theory of mind (see also Meltzoff 1995, 2007, 2011). As many children with ASD are shown to have deficits in performing theory of mind tasks, the main results of this study are in line with theory of mind and executive function theories of autism, which posit early deficits in the understanding of intentionality (Baron-Cohen 2001). However, longitudinal research in children with ASD measuring both the understanding of intentions and theory of mind deficits would be necessary to further investigate this possible relation.

Several studies show that behavioral strategies can be used to teach children with ASD imitation skills (e.g., Cardon and Wilcox 2011; Ganz et al. 2008). Instead of teaching these behaviors to children with ASD and ID, future studies may use behavioral strategies to increase the reinforcing value of social stimuli by systematically pairing tangible with social reinforcers to enhance social orientating in children with ASD and ID. It should be investigated if the increase in social orientating has a collateral effect on social learning behaviors that were not targeted during treatment (e.g., imitation, joint attention) and development.

Author Contribution All authors read and approved the final manuscript. NPS: designed and executed the study, analyzed the data, and wrote the paper. RD: collaborated with the design and writing of the study. HK: assisted with the data analyses and writing of the study. LV: collaborated with the design of the study and the editing of the final manuscript.

\section{Compliance with Ethical Standards}

Conflict of Interest Statement The authors declare that there is no conflict of interest.

Ethics Statement Ethical approval of the study was obtained from the ethics committee of the Radboud University and the ethics committees of some of the sites the participants visited.

Informed Consent Statement Informed consent was obtained from all individual participants included in the study.

Open Access This article is distributed under the terms of the Creative Commons Attribution 4.0 International License (http:// creativecommons.org/licenses/by/4.0/), which permits unrestricted use, distribution, and reproduction in any medium, provided you give appropriate credit to the original author(s) and the source, provide a link to the Creative Commons license, and indicate if changes were made.

\section{References}

Aldridge, M. A., Stone, K. R., Sweeney, M. H., \& Bower, T. G. R. (2000). Preverbal children with autism understand the intentions of others. Developmental Science, 3, 294-301. https://oi.org/10.1111/14677687.00123.

Baron-Cohen, S. (2001). Theory of mind and autism: a review. International Review of Research in Mental Retardation, 23, 169184. https://doi.org/10.1016/S0074-7750(00)80010-5.

Behne, T., Carpenter, M., Call, J., \& Tomasello, M. (2005). Unwilling versus unable: infants' understanding of intentional action. Developmental Psychology, 41, 328-337. https://doi.org/10.1037/ 0012-1649.41.2.328.

Bellagamba, F., \& Tomasello, M. (1999). Re-enacting intended acts: comparing 12- and 18-month-olds. Infant Behavior and Development, 22, 277-282. https://doi.org/10.1016/S01636383(99)00002-8.

Bellagamba, F., Camaioni, L., \& Colonnesi, C. (2006). Change in children's understanding of other's intentional actions. Developmental Science, 9, 182-188. https://doi.org/10.1111/j.1467-7687.2006. 00478.x.

Brooks, R., \& Meltzoff, A. N. (2008). Infant gaze following and pointing predict accelerated vocabulary growth through two years of age: a longitudinal, growth curve modeling study. Journal of Child Language, 35, 207-220. https://doi.org/10.1017/ S030500090700829X.

Cardon, T., \& Wilcox, M. J. (2011). Promoting imitation in young children with autism: a comparison of reciprocal imitation training and 
video modeling. Journal of Autism and Developmental Disorders, 41, 654-666. https://doi.org/10.1007/s10803-010-1086-8.

Carpenter, M., Pennington, B. F., \& Rogers, S. J. (2001). Understanding of others' intentions in children with autism. Journal of Autism and Developmental Disorders, 31, 589-599. https://doi.org/10.1023/A: 1013251112392.

Castelloe, P., \& Dawson, G. (1993). Subclassification of children with autism and pervasive developmental disorder: a questionnaire based on wing's subgrouping scheme. Journal of Autism and Developmental Disorders, 23(2), 229-241.

Cicchetti, D. V. (1994). Guidelines, criteria, and rules of thumb for evaluating normed and standardized assessment instruments in psychology. Psychological Assessment, 6, 284-290. https://doi.org/10. 1037/1040-3590.6.4.284.

Cohen, J. (1988). Statistical power analysis for the behavioral sciences (2nd ed.). New Jersey: Lawrence Erlbaum.

Colonnesi, C., Rieffe, C., Koops, W., \& Perucchini, P. (2008). Precursors of a theory of mind: a longitudinal study. British Journal of Developmental Psychology, 26, 561-577. https://doi.org/10.1348/ $026151008 X 285660$.

Dawson, G., Meltzoff, A. N., Osterling, J., Rinaldi, J., \& Brown, E. (1998). Children with autism fail to orient to naturally occurring social stimuli. Journal of Autism and Developmental Disorders, 28, 479-485. https://doi.org/10.1023/A:1026043926488.

Dawson, G., Webb, S., \& McPartland, J. (2005). Understanding the nature of face processing impairment in autism: insights from behavioral and electrophysiological studies. Developmental Neuropsychology, 27, 403-424. https://doi.org/10.1207/ s15326942dn2703 6.

Didden, R., Sigafoos, J., Green, V. A., Korzilius, H., Mouws, C., Lancioni, G. E., O'Reilly, M. F. O., \& Curfs, L. M. G. (2008). Behavioral flexibility in individuals with angelman syndrome, Down syndrome, non-specific intellectual disability and autism spectrum disorder. Journal of Intellectual Disability Research, 52, 503-509. https://doi.org/10.1111/j.1365-2788.2008.01055.x.

Dunn, L., \& Dunn, L. (1997). Peabody picture vocabulary test-revised. Circle Pines, MN: American Guidance Services.

Ganz, J. B., Bourgeois, B. C., Flores, M. M., \& Campos, B. A. (2008). Implementing visually cued imitation training with children with autism spectrum disorders and developmental delays. Journal of Positive Behavior Intervention, 10, 56-66. https://doi.org/10.1177/ 1098300707311388

Gergely, G., \& Watson, J. (1999). Early socio-emotional development: contingency perception and the social-biofeedback model. In P. Rochat (Ed.), Early social cognition (pp. 101-136). Mahwah, New Jersey: Lawrence Erlbaum Associates.

Heimann, M., Strid, K., Smith, L., Tjus, T., Ulvund, S. E., \& Meltzoff, A. N. (2006). Exploring the relation between memory, gestural communication, and the emergence of language in infancy: a longitudinal study. Infant and Child Development, 15, 233-249. https://doi. org/10.1002/icd.462.

Hobson, R. P., \& Lee, A. (1999). Imitation and identification in autism. Journal of Child Psychology and Psychiatry, 40, 649-659. https:// doi.org/10.1111/1469-7610.00481.

Huang, C. T., Heyes, C., \& Charman, T. (2002). Infants' behavioral reenactment of 'failed attempts': exploring the roles of emulation learning, stimulus enhancement and understanding of intentions. Developmental Psychology, 38, 840-855. https://doi.org/10.1037/ 0012-1649.38.5.840.

Ingersoll, B. (2008). The effect of context on imitation skills in children with autism. Research in Autism Spectrum Disorders, 2, 332-340. https://doi.org/10.1016/j.rasd.2007.08.003.

Ingersoll, B., \& Schreibman, L. (2006). Teaching reciprocal imitation skills to young children with autism using a naturalistic behavioral approach: effects on language, pretend play and joint attention.
Journal of Autism and Developmental Disorders, 36, 487-505. https://doi.org/10.1007/s10803-006-0089-y.

Johnson, S. C., Booth, A., \& O'Hearn, K. (2001). Inferring the goals of a nonhuman agent. Cognitive Development, 16, 637-656. https://doi. org/10.1016/S0885-2014(01)00043-0.

Kuhl, P. K., Coffey-Corina, S., Padden, D., \& Dawson, G. (2005). Links between social and linguistic processing of speech in preschool children with autism: behavioral and electrophysical measures. Developmental Science, 8, F1-F12. https://doi.org/10.1111/j.14677687.2004.00384.x.

Lord, C., Rutter, M., \& LeCouteur, A. (1994). Autism diagnostic interview-revised: a revised version of a diagnostic interview for caregivers of individuals with possible pervasive disorders. Journal of Autism and Developmental Disorders, 24, 659-685. https://doi.org/ 10.1007/BF02172145.

Lord, C., Rutter, M., DiLavore, P. C., \& Risi, S. (2006). Autism diagnostic observation schedule. Western Psychological Service: Los Angeles.

Meltzoff, A. (1995). Understanding the intentions of others: re-enactment of intended acts by 18 -month old children. Developmental Psychology, 31, 838-850. https://doi.org/10.1037/0012-1649.31.5. 838.

Meltzoff, A. N. (2007). 'Like me': a foundation for social cognition. Developmental Science, 10, 126-134. https://doi.org/10.1111/j. 1467-7687.2007.00574.x.

Meltzoff, A. N. (2011). Social cognition and the origins of imitation, empathy, and theory of mind. In U. Goswami (Ed.), The WileyBlackwell handbook of childhood cognitive development (pp. 4975). Malden, MA: Wiley Blackwell.

Mullen, E. M. (1995). Mullen scales of early learning (AGS ed.). Minneapolis: Pearson.

Mundy, P., Delgado, C., Block, J., Venezia, M., Hogan, A. \& Seibert, J. (2003). A manual for the Abridged Early Social Communication Scales (ESCS). Retrieved march 1, 2011 from http://www.ucdmc. ucdavis.edu/mindinstitute/ourteam/faculty_staff/ESCS.pdf.

Munson, J., Faja, S., Meltzoff, A., Abbott, R., \& Dawson, G. (2008). Neurocognitive predictors of social and communicative developmental trajectories in preschoolers with autism spectrum disorders. Journal of the International Neuropsychological Society, 14, 956 966. https://doi.org/10.1017/S1355617708081393.

Peters-Scheffer, N., Didden, R., Green, V. A., Sigafoos, J., Korzilius, H., Pituch, K., O'Reilly, M. F., \& Lancioni, G. (2008). The behavior flexibility rating scale-revised (BFRS-R): factor analysis, internal consistency, inter-rater and intra-rater reliability, and convergent validity. Research in Developmental Disabilities, 29, 398-407. https:// doi.org/10.1016/j.ridd.2007.07.004.

Rogers, S. J., \& Pennington, B. F. (1991). A theoretical approach to the deficits in infantile autism. Development and Psychopathology, 3, 137-162. https://doi.org/10.1017/S0954579400000043.

Schlichting, J. E. P. T., van Eldik, M. C. M., Lutje Spelberg, H. C., van der Meulen, S. J., \& van der Meulen, B. F. (1995). Schlichting test voor taalproductie. Nijmegen: Berkhout.

Schopler, E., Reichler, R. J., \& Rochen Renner, B. (2007). The Childhood Autism Rating Scale. Los Angeles: Western Psychology Services.

Schultz, R. T. (2005). Developmental deficits in social perception in autism: the role of the amygdala and fusiform face area. International Journal of Developmental Neuroscience, 23, 125141. https://doi.org/10.1016/j.ijdevneu.2004.12.012.

Scott-Van Zeeland, A. A., Dapretto, M., Ghahremani, D. G., Poldrack, R. A., \& Bookheimer, S. Y. (2010). Reward processing in autism. Autism Research, 3, 53-67. https://doi.org/10.1002/aur.122.

Smith, I. M., \& Bryson, S. E. (1994). Imitation and action in autism: a critical review. Psychological Bulletin, 116, 259-273. https://doi. org/10.1037/0033-2909.116.2.259.

Snijders, J. T., Tellegen, P. J., Winkel, M., \& Laros, J. A. (1996). SON-R 2,5-7 Snijders Oomen Niet-verbale Intelligentietest-Revisie [SON- 
$R$ 2,5-7 Snijders-Oomen Nonverbal Intelligence Test—Revised]. Lisse: Swets \& Zeitlinger.

Sparrow, S., Balla, D., \& Cicchetti, D. (1984). Vineland adaptive behavior scales (Interview ed.). Circle Pines, MN: American Guidance Service.

Stone, W. L., Ousley, O. Y., \& Littleford, C. D. (1997). Motor imitation in young children with autism: what's the object? Journal of Abnormal Psychology, 25, 475-485. https://doi.org/10.1023/A: 1022685731726.

Tomasello, M. (1999). The cultural origins of human cognition. London: Harvard university press.

Tomasello, M., Savage-Rumbaugh, S., \& Kruger, A. C. (1993). Imitative learning of actions on objects by children, chimpanzees and enculturated chimpanzees. Child Development, 64, 1688-1705. https://doi.org/10.2307/1131463.

Tomasello, M., Carpenter, M., Call, J., Behne, T., \& Moll, H. (2005). Understanding and sharing intentions: the origins of cultural cognition. Behavioral and Brain Sciences, 28, 675-735. https://doi.org/ 10.1017/S0140525X05000129.

Toth, K., Munson, J., Meltzoff, A. N., \& Dawson, G. (2006). Early predictors of communication development in young children with autism spectrum disorder: joint attention, imitation and toy play.
Journal of Autism and Developmental Disorders, 36, 993-1005. https://doi.org/10.1007/s10803-006-0137-7.

Van der Meulen, B. F., Ruiter, S. A. J., Lutje Spelberg, H. C., \& Smrkovsky', M. (2002). Bayley Scales of Infant Development-II. Nederlandse versie. Handleiding. Amsterdam: Harcourt.

Van Eldik, M. C. M., Schlichting, L. E. P. T., Lutje Spelberg, H. C., van der Meulen, B. F., \& van der Meulen, S. J. (1995). Reynell test voor Taalbegrip handleiding. Nijmegen: Berkhout.

Vanvuchelen, M., Roeyers, H., \& de Weerdt, W. (2011). Do imitation problems reflect a core characteristic in autism? Evidence from a literature review. Research in Autism Spectrum Disorders, 5, 89-95. https://doi.org/10.1016/j.rasd.2010.07.010.

Williams, J. H. G., Whiten, A., \& Singh, T. (2004). A systematic review of action imitation in autism spectrum disorder. Journal of Autism and Developmental Disorders, 34(3), 285-299.

Wing, L., \& Gould, J. (1979). Severe impairments of social interaction and associated abnormalities in children: epidemiology and classification. Journal of Autism and Developmental Disorders, 9(1), 11-29.

Zachor, D. A., Ilanit, T., \& Ben Itzchak, E. (2010). Autism severity and motor abilities correlates of imitation situations in children with autism spectrum disorders. Research in Autism Spectrum Disorders, 4, 438-443. https://doi.org/10.1016/j.rasd.2009.10.016. 